\title{
Incorporating climate change into systematic conservation planning
}

\author{
Craig R. Groves • Edward T. Game • Mark G. Anderson • \\ Molly Cross $\cdot$ Carolyn Enquist $\cdot$ Zach Ferdaña $\cdot$ Evan Girvetz $\cdot$ \\ Anne Gondor • Kimberly R. Hall • Jonathan Higgins • Rob Marshall • \\ Ken Popper $\cdot$ Steve Schill $\cdot$ Sarah L. Shafer
}

Received: 27 October 2011/Accepted: 25 February 2012/Published online: 17 March 2012

(C) The Author(s) 2012. This article is published with open access at Springerlink.com

\begin{abstract}
The principles of systematic conservation planning are now widely used by governments and non-government organizations alike to develop biodiversity conservation plans for countries, states, regions, and ecoregions. Many of the species and ecosystems these plans were designed to conserve are now being affected by climate change, and there is a critical need to incorporate new and complementary approaches into these plans that will aid species and ecosystems in adjusting to potential climate change impacts. We propose five approaches to climate change adaptation that can be integrated into existing or
\end{abstract}

C. R. Groves $(\bowtie)$

The Nature Conservancy, Conservation Science Group, 40 E. Main Street, Bozeman, MT 59715, USA

e-mail: craig_groves@tnc.org

E. T. Game

The Nature Conservancy, Conservation Science Group, 51 Edmondstone Street, South Brisbane, QLD 4101, Australia

M. G. Anderson

The Nature Conservancy, Eastern North America Division, 99 Bedford Street 5th Floor, Boston, MA 02111, USA

M. Cross

Wildlife Conservation Society, North America Program, 301 N. Willson Ave, Bozeman, MT 59715, USA

C. Enquist

National Phenology Network and The Wildlife Society, 1955 E. 6th Street, Tucson,

AZ 85721, USA

Z. Ferdaña

The Nature Conservancy, Global Marine Team, 1917 First Avenue,

Seattle, WA 98101, USA

E. Girvetz

University of Washington and The Nature Conservancy, Global Climate Team, 1917 First Avenue,

Seattle, WA 98101, USA 
new biodiversity conservation plans: (1) conserving the geophysical stage, (2) protecting climatic refugia, (3) enhancing regional connectivity, (4) sustaining ecosystem process and function, and (5) capitalizing on opportunities emerging in response to climate change. We discuss both key assumptions behind each approach and the trade-offs involved in using the approach for conservation planning. We also summarize additional data beyond those typically used in systematic conservation plans required to implement these approaches. A major strength of these approaches is that they are largely robust to the uncertainty in how climate impacts may manifest in any given region.

Keywords Climate refugia - Geophysical stage $\cdot$ Connectivity Ecosystem function and process $\cdot$ Climate change adaptation

\title{
Introduction
}

Systematic conservation planning (Margules and Pressey 2000) is now commonly practiced around the world from local to regional and national levels, and is mandated by several international or national agreements (Groves 2003). This planning approach aims to ensure that societies "have a plan" for conserving biodiversity and critical habitats in the face of impacts from urban development, agricultural land conversion, resource extraction, major infrastructure development, and other activities that alter the patterns and processes of natural ecosystems. The methods used to produce these plans originated 30 years ago (Kirkpatrick 1983; Pressey 2002) before climate change was widely recognized. As worldwide emissions of greenhouse gases over the past decade have been on a steeply increasing trend (Raupach et al. 2007; Le Quere et al. 2009; Manning et al. 2010), there is an urgent need to develop updated planning approaches to provide for biodiversity conservation in the face of altered climates. In this paper, we outline five major approaches for incorporating climate change into conservation plans to improve the chances that these plans and priorities will remain effective as climate changes.

\author{
A. Gondor \\ The Nature Conservancy, Gulf of California and Pacific Program, 1510 E. Fort Lowell Boulevard, \\ Tucson, AZ 85719, USA \\ K. R. Hall \\ The Nature Conservancy, Great Lakes Program, 101 E. Grand River Avenue, Lansing, MI 48906, USA \\ J. Higgins \\ The Nature Conservancy, Global Freshwater Team, 8 S Michigan Ave, Suite 2301, \\ Chicago, IL 60603, USA \\ R. Marshall \\ The Nature Conservancy, Arizona Program, 1510 E. Fort Lowell Boulevard, Tucson, AZ 85719, USA
}

K. Popper

The Nature Conservancy, Oregon Program, 821 SE 14th Ave, Portland, OR 97214, USA

S. Schill

The Nature Conservancy, Caribbean Program, 571 E 3050 N, Provo, UT 84604, USA

S. L. Shafer

U.S. Geological Survey, 3200 SW Jefferson Way, Corvallis, OR 97331, USA 
The development of systematic conservation plans helps guide where we should work to efficiently achieve conservation objectives, which of these places are the highest priorities, and increasingly, how we should work in these places (Redford et al. 2003; Wilson et al. 2007). Although early efforts at such planning focused largely on conserving the species, communities, or ecosystems of a specific region, the science of conservation planning is now advancing to better incorporate ecological processes and more recently, ecosystem services (Egoh et al. 2007).

Despite these advances, many of the species and ecosystems for which these conservation plans were developed are likely to be facing ever increasing stresses due to the direct and indirect effects of climate change. The recent Intergovernmental Panel on Climate Change Fourth Assessment Report (IPCC 2007a) suggests that 10-40\% of species will be at high risk of extinction as global mean temperature reaches $2-3^{\circ} \mathrm{C}$ above pre-industrial levels. Under projected future climate changes, ecosystems will be affected by the resulting changes in sea-level rise, ocean acidification, changes in the pattern and intensity of precipitation, change in wind direction and speed, and reductions in snow/ice cover and permafrost. Clear evidence that climate change is already acting as a stressor include coral reef bleaching, shifts in species ranges, and local extinctions, as well as more subtle changes in growing seasons, drought stress, migration patterns, primary production, and species interactions, just to name a few (Donner et al. 2005; Parmesan 2006; Foden et al. 2008; Sinervo et al. 2010; Breshears et al. 2009). Conservation planners, scientists, and practitioners are adapting approaches to address both altered ecological systems and human responses to climate-induced changes within these ecosystems (Marshall et al. 2010) to help ensure the continued relevance and effectiveness of conservation efforts.

Climate change adaptation refers to the adjustment of natural or anthropogenic systems to a changing climate for the purpose of moderating impacts or capitalizing on novel opportunities (IPCC 2007b). We argue that integrating adaptation into systematic conservation planning is imperative for four reasons. First, systematic planning processes are frequently used to establish conservation priorities of government and non-governmental organizations alike, and adaptation has a central role to play in developing these priorities. Second, compared to most single-site-focused conservation plans, systematic conservation plans typically inform decisions at a spatial scale that is well matched to the resolution of many climate change projections. Although systematic conservation planning is not restricted to a particular spatial scale, it is most commonly used to guide conservation investment at regional and ecoregional scales on the order of $10^{3}$ to $10^{4} \mathrm{~km}^{2}$, a scale similar to the spatial scale of many projected climate change impacts (Wiens and Bachelet 2010). Third, effectively responding to the challenges posed by climate change will require regionally coordinated management responses that extend beyond the borders of most typical site-focused conservation projects (Heller and Zavaleta 2009). Finally, the methods and data supporting systematic planning have typically been based on static interpretations of biodiversity (Pressey et al. 2007), whereas more dynamic interpretations of biodiversity are necessary to accommodate many climate change impacts and adaptation considerations.

Conservation scientists, planners, and practitioners are actively exploring options for climate change adaptation (e.g., Araújo 2009; Ferdaña et al. 2010; Hansen et al. 2010). Several recent papers have summarized recommendations for adaptation strategies and actions (Kareiva et al. 2008; Heller and Zavaleta 2009; Mawdsley et al. 2009; Millar et al. 2007; Lawler et al. 2009; Hansen et al. 2010; Poiani et al. 2011; Rowland et al. 2011). In many cases, these recommendations from the scientific community are vague, 
with the step of translating a particular principle to a specific type of decision or planning process left to the practitioner (Heller and Zavaleta 2009). In other cases, they rely heavily on modeled simulations of future climate changes that are too uncertain to be a reliable foundation for conservation planning (Beier and Brost 2010). In contrast, we describe five explicit adaptation approaches that can be incorporated into regionalscale conservation plans, trade-offs involved in their application, assumptions implicit in their use, and additional data that may be required for their implementation: (1) conserving the geophysical stage, (2) protecting climatic refugia, (3) enhancing regional connectivity, (4) sustaining ecosystem process and function, and (5) capitalizing on conservation opportunities emerging in response to climate change (e.g., Reducing Emissions from Deforestation and Forest Degradation [REDD]). Although by no means an exhaustive list, these approaches encompass what we believe are the most significant opportunities for integrating adaptation considerations into new or existing biodiversity conservation plans.

\section{Conserving the geophysical stage}

Hunter et al. (1988) first suggested a strategy to address climate change by conserving a diversity of landscape units defined by topography and soils. Since that time, several conservation plans have relied on combinations of soil and topographic variables as surrogates for biodiversity features for regions that lack biological inventories to underpin regional planning exercises (see Table 1 in Beier and Brost 2010). Given the uncertainties associated with projections of future climate changes and their spatial expression, the use of geophysical variables as planning elements has resurfaced as a practical alternative to conservation planning approaches that rely on modeling of potential climate change impacts.

At its core, this approach involves focusing conservation efforts on the underlying physical environment - the metaphorical stage-instead of the species or the actors. A recent analysis by Anderson and Ferree (2010) in the northeastern United States provides strong evidence for the merits of this "saving the stage" strategy. They demonstrated that the number of species found in 14 northeastern states and adjacent provinces can be accurately predicted from the number of geologic classes, the elevation range, the latitude, and the amount of limestone bedrock (Fig. 1). If geophysical diversity maintains species diversity, then conserving geophysical settings offers an approach to conservation that conserves diversity under both current and future climates, although the species constituting the diversity may change through time.

Beier and Brost (2010) advocate using recurring landscape units as conservation features. These units, which they call land facets, are defined on the basis of geology, soil, and topography and are similar to those used by Anderson and Ferree (2010). Based on findings from several previous studies, they argue that such units can serve as useful surrogates for today's biodiversity and tomorrow's climate-driven range shifts, and help conserve ecological and evolutionary processes. Because land facets cannot serve as surrogates for all species (Beier and Brost 2010), such an approach should be used as a complement to existing systematic conservation planning processes that also focus on land cover and species as conservation features.

For conservation organizations, this approach to adaptation requires a shift from focusing on individual species and communities or ecosystems defined by dominant vegetation to geophysical settings. However, this shift is neither philosophically nor practically as large as it might seem. For example, Anderson and Ferree (2010) 


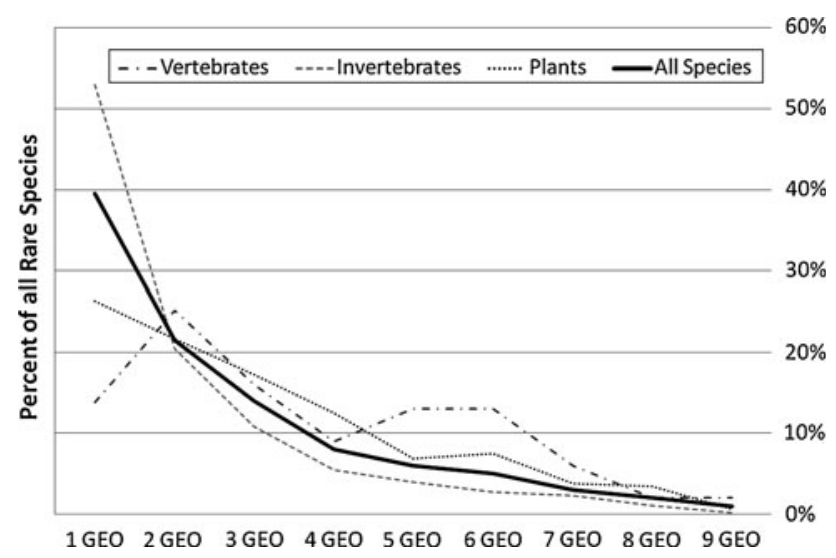

Fig. 1 The proportion of rare species classes restricted to single or multiple geology classes in 14 state and provinces in northeastern North America. The number of both rare species and all species in each state and province can be accurately predicted with certainty by four geophysical factors, including geology class. These results strongly suggest that conserving the diversity of geophysical settings is a robust strategy for conserving the current and future composition of biodiversity under climate change scenarios. Reprinted from PloS ONE (Anderson and Ferree 2010)

demonstrated that most rare species and community types that many conservation organizations in the northeastern U.S. strive to conserve already represent unique environmental settings, precisely because species and settings are so correlated. In addition, systematic planning efforts in the marine and freshwater realm already focus on physical habitats because of the lack of biodiversity information for many of these communities (Higgins et al. 2005).

\section{Assumptions}

The conserving the stage approach is predicated on the assumption that geophysical units can serve as adequate surrogates for the current and future distribution of biodiversity, even under climate change scenarios. Previous studies (e.g., Pressey et al. 2000; Araújo et al. 2001) have demonstrated that such surrogates are adequate for many species, but certainly not all. An underlying assumption is that the diversity and distribution of terrestrial ecological communities is to a large extent driven by diversity in the underlying geophysical variables. This will not always be true, especially for large mammals and birds that tend to be less strongly tied to particular soil types and microhabitats. The strength of the relationship between geophysical settings and biodiversity is likely to vary among regions. Areas with less variation in underlying geology and topography, areas with a high degree of land conversion, a relatively young flora and fauna (e.g., due to recent glaciations), or areas where changes in local climatic gradients could alter today's geophysical stage may not be as well-suited as others to the use of this approach. In addition, correlations of the abiotic environment with species richness across broad spatial scales such as in (U.S.) states (Anderson and Ferree 2010) do not necessarily inform the on-the-ground conservation efforts for biodiversity that usually happen at much finer spatial scales. Conserving the stage assumes that conservation objectives are primarily related to biodiversity representation. If regional conservation objectives seek to conserve particular species or communities, approaches that are more tailored to these goals and the particular stressors on these conservation features will be needed. 
Trade-offs

Of the five approaches to adaptation addressed here, conserving the stage arguably involves the fewest trade-offs to be evaluated. Further, this approach integrates well with a goal of considering current and historic refugia, as many of the same characteristics and principles apply. It is easily used in conjunction with existing species or habitat features, and doing so is unlikely to reduce the efficiency of the conservation planning process. One advantage of the conserving the stage approach is that it does not resist change, but rather anticipates ecological and evolutionary dynamism and uses our understanding of how biodiversity is generated to maximize the opportunity for future diversity.

\section{Protecting climatic refugia}

In many ecosystems, climate change is already leading to rapid ecological change that can be construed as negative for biodiversity conservation (e.g., bleaching events for coral reefs-Berkelmans et al. 2004; drought-related mortality of Pinus edulis in the southwestern United States-Breshears et al. 2005). Because the probability, speed, type, and extent of these changes is unlikely to be uniform across a region, a relatively straight forward and intuitive approach to adaptation in regional conservation plans is to focus on identifying and protecting biodiversity in those areas least likely to undergo rapid climateinduced changes. Such places may serve as important climate refugia for species and habitats that become marginalized through ecological changes elsewhere. Climate refugia can exist both in places where changes in climate are attenuated (e.g., Saxon 2008), or where biodiversity is likely to be particularly robust to changes in climate, perhaps due to a broad climate tolerance (e.g., West and Salm 2003). For example, as part of a national conservation plan for Papua New Guinea (PNG), Game et al. (2011) identified climate refugia based on projected changes in seven climate dependent variables (potential evapotranspiration, precipitation/potential evapotranspiration, precipitation of the coldest quarter of the year, precipitation of the warmest quarter of the year, mean temperature of the coldest quarter of the year, mean temperature of the warmest quarter of the year, and average monthly temperature) (Fig. 2). The current value for these variables in 5-km pixels was compared with their projected value in the year 2100, and the expected change normalised with the value 1 being assigned to the pixel expected to experience the greatest climatic change across PNG.

There are multiple ways to define refugia from climate change, and different definitions require different methods of identification and data inputs. Ashcroft (2010) recommends that discussions of refugia explicitly distinguish between macrorefugia and microrefugia (i.e., the scale at which refugia are being identified, and therefore what resolution climate data are necessary or appropriate), in situ and ex situ refugia (whether refugia from future climate change are likely to be located within or outside of a species' current distribution), and refugia based on climatic versus habitat stability. The issue of scale is particularly important as it has been shown to influence patterns of species richness and species turnover, particularly as they relate to changes along environmental gradients (Jetz and Rahbeck 2002). For example, species turnover in amphibians and birds is closely linked to environmental turnover, and this effect is more pronounced in tropical than temperate realms (Buckley and Jetz 2008), suggesting that tropical systems may be more susceptible to impacts from climate change. These results suggest that some areas identified as refugia 


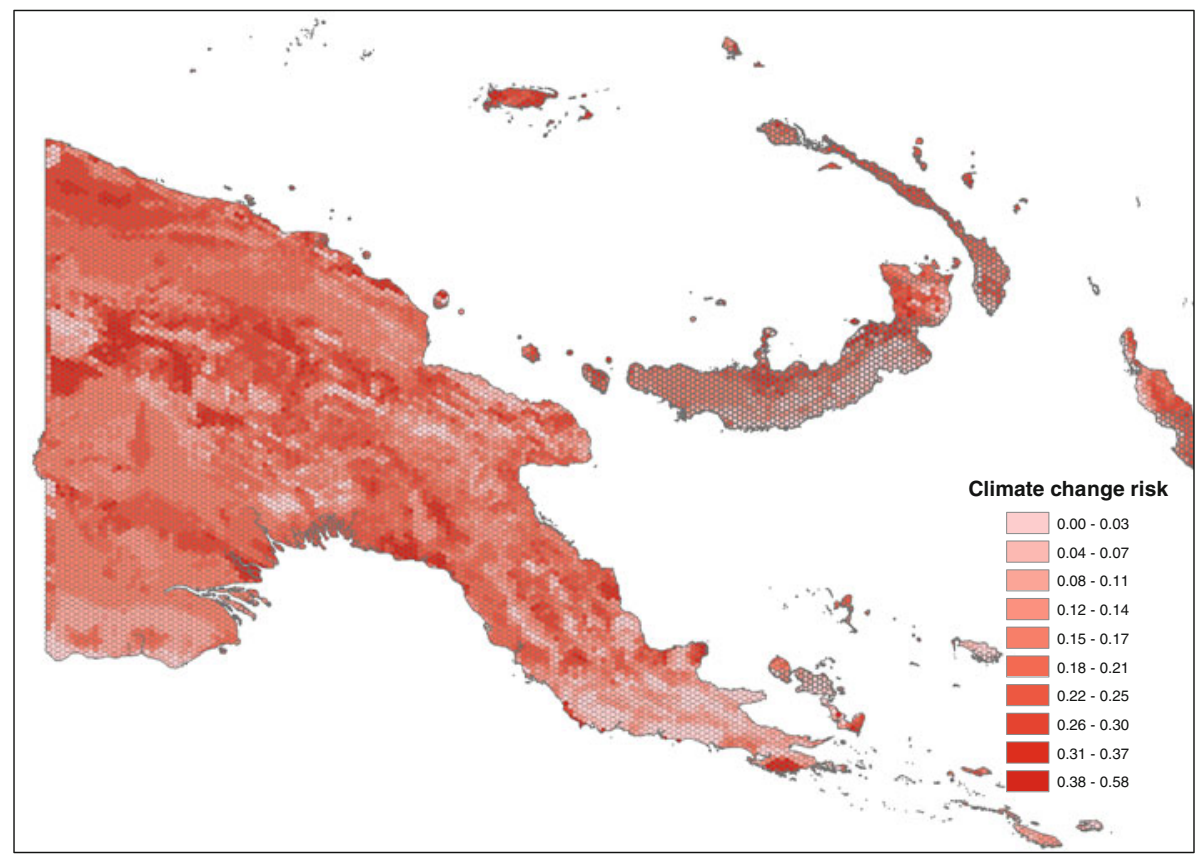

Fig. 2 Projected severity of climate change for Papua New Guinea, normalized to a scale from 0 (less change expected) to 1 (more change expected) and summarized by 5000 ha planning units. This data layer was developed using methods described in Saxon et al. (2005) and was then used in a decision support system (Marxan) to identify climate refugia as part of a broader regional conservation assessment for the Papua New Guinea government

and also containing high species richness and turnover may represent "win-win" situations for conservationists.

Conserving climate refugia represents only a partial solution to climate change adaptation. Many areas exposed to large climatic changes may become or remain important areas for biodiversity even if they contain a different suite of species. Similarly, identifying refugia relies largely on climate projections with all their associated uncertainties. While it is particularly hard to predict what species and communities are likely to colonize an area as a result of climate change, we have a better ability to predict what species and communities may be lost from an area. Conserving projected refugia will offer some ecosystems a better chance of adapting to climate change, but it certainly does not guarantee their viability. As such, the potential for an area to serve as a refugium should not be used as the sole basis for identifying important conservation areas.

A recent modification of the climate refugia approach involves identifying areas where high topographic diversity creates a wide array of microclimates in close proximity (Ashcroft et al. 2009; Fridley 2009). Because coarse-scale climate envelope models often fail to capture topographic or "microclimatic buffering" (Willis and Bhagwat 2009), they may overestimate or misrepresent the projected extinction rates for a given area. Thus, the climates experienced by individual organisms may differ dramatically from the regional norm and species are likely to shift their locations to take advantage of nearby microclimates. 
Assumptions

The utility of identifying climate refugia during systematic conservation assessments depends on at least three assumptions. First, identifying refugia solely on projected climatic changes assumes that ecological changes are directly related to the degree of climate change and that changes will be least severe in those places where climate remains relatively constant. Second, prioritizing those areas least likely to change assumes that climate impacts are beyond our control and therefore worth avoiding where possible. Neither of these assumptions will always hold. Climate is projected to change through time and areas that are refugia for a species in the near term may not persist as refugia over longer time scales. There are also many ways in which we can affect the impacts of climate change. For example, protecting coral reefs from fishing can improve their ability to resist climate change (e.g., Game et al. 2008a). Third, identifying refugia on the basis of species' expected response to climate change, assumes that we have sufficient knowledge to do so, an assumption that likely will only hold for a relatively small number of species.

\section{Trade-offs}

Potential gains in biodiversity persistence achieved through conserving climate refugia may have to be balanced against other considerations, such as the cost of conserving areas. If areas of relative climate stability also represent desirable places for other uses, such as farming or fishing, then focusing conservation efforts on these places will likely require greater resources and compromises. Because we are dealing with probabilities not certainties when considering refugia, if it proved particularly costly to conserve areas at lower risk from climate-related changes, an analysis of this trade-off might suggest it is most efficient to instead increase the total area in conservation by protecting more vulnerable but also cheaper sites (e.g., Game et al. 2008b). Additionally, because identifying areas robust to climate change will often rely on modeled climate projections, it introduces both greater uncertainty and greater cost into conservation decisions. It is important to be explicit about these costs and trade-offs, and confident these prices are worth paying. In a sense, climate refugia imply an assumption that change can be resisted rather than adapted to. Even if climate does not impact an area identified as a refugium, changes due to invasive species, airborne pollution, and other environmental stresses may alter refugia, and these changes could render some climate "refugia" as low priorities for conservation.

\section{Enhancing regional connectivity}

Increasing landscape, watershed, and seascape connectivity is the most commonly cited climate change adaptation approach for biodiversity management (Heller and Zavaleta 2009). From an adaptation perspective, maintaining or improving the linkages between conservation areas serves at least two purposes. First, it provides the best opportunity for the natural adaptation of species and communities that will respond to climate change by shifting their distribution (Fig. 3). Second, improving connectivity can improve the ecological integrity of conservation areas, thereby enhancing the resilience of ecosystems to changes in disturbance regimes characteristic of climate change in many places. Even in the absence of climate change, connectivity is considered important to prevent isolation of populations and ecosystems, provide for species with large home ranges (e.g., wide- 


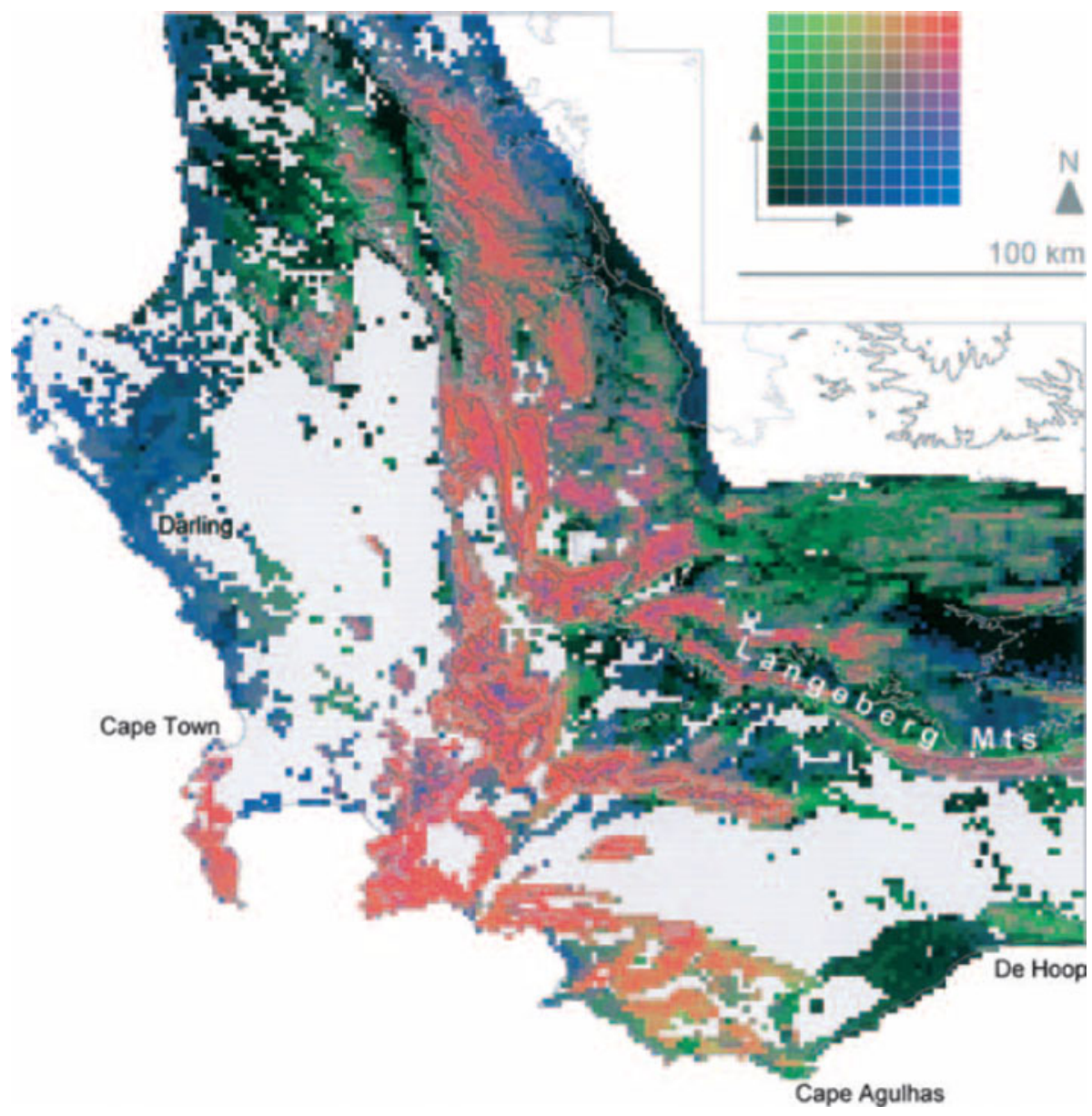

Fig. 3 Dispersal corridors necessary for movement to newly suitable areas under climate change scenarios, identified for 280 species of Proteaceae in the Cape Floristic Region of South Africa. Colors on the $Y$-axis indicate increasing numbers of dispersal chains or corridors while colors on the $X$-axis represent increasing numbers of species based on species richness data for the year 2000. Used by permission from John Wiley and Sons (Williams et al. 2005)

ranging carnivores), provide for access of species to different habitats to complete life cycles, to maintain ecological processes such as water flow (Khoury et al. 2010), and to alleviate problems deriving from multiple meta-populations that are below viability thresholds (Hilty et al. 2006). As a result, many regional assessments already consider the connectivity of conservation areas, albeit with varying degrees of sophistication.

The term connectivity has taken on many meanings in the context of biodiversity conservation. Crooks and Sanjayan (2006) identify two primary components of connectivity: "(1) the structural (or physical) component: the spatial arrangement of different types of habitat or other elements in the landscape, and (2) the functional (or behavioral) component: the behavioral response of individual, species or ecological processes to the physical structure of the landscape." Connectivity has longitudinal, lateral (e.g., rivers to floodplains), vertical (e.g., recharge of subterranean ground water) and temporal (e.g., 
changing habitat distributions through time) dimensions. In regional conservation, connectivity has most commonly focused on developing corridors between areas to accommodate animal movement (e.g., Bruinderink et al. 2003; Fuller et al. 2006), and aquatic connectivity for fish migrations (e.g., Schick and Lindley 2007; Khoury et al. 2010). However, connectivity is also critical for the movement of water, sediment and nutrients, especially in marine and freshwater systems (Abrantes and Sheaves 2010; Beger et al. 2010; Khoury et al. 2010). Temporal connectivity has not received the same attention as spatial connectivity, but is likely critical in the creation of climatic refugia, such as during prolonged drought periods (Klein et al. 2009).

At regional scales, conservation planners can affect connectivity in four general ways: altering the size, placement and number of conservation areas; changing the shape and orientation of conservation areas; adding specific linkages between conservation areas; and improving management of the intervening land, water and sea matrix. Regional conservation plans can inform each of these decisions.

Although improving connectivity is a commonly recommended and widely applicable approach to adaptation (Heller and Zavaleta 2009; Krosby et al. 2010; Beier et al. 2011), implementing it can be difficult. First, we lack a complete understanding of exactly what types and locations of connectivity are needed to enable climate change-induced species movements, and whether they are similar to or different from connectivity needs under current climate conditions (Cross et al. 2012). Second, the optimal connectivity pattern will be different for nearly every species and community. Third, for most species we know very little about their connectivity needs and can answer the "how much is enough" question for only a few species-often large carnivores that are highly mobile and arguably the least challenged by movements needed for climate adaptation. A fourth challenge is determining how to measure and map connectivity patterns. There are many new metrics for doing such measurements, but each comes with its own set of assumptions and technical requirements (Beier et al. 2008; McRae et al. 2008). Fifth, most connectivity modeling of species or habitats is focused on their current distributions, which will likely prove inadequate for many species whose distributions will be changing. Finally, the suitability of corridor areas may change over time as climate changes (Williams et al. 2005).

\section{Assumptions}

The most significant assumption associated with the connectivity approach is that improving connectivity will facilitate natural adaptation and increased persistence of species and communities in conservation areas. Specifically, we assume that we can identify what factors limit movement of species or the continuation of natural processes, and that we can identify, and ideally be able to measure, a change in connectivity (Hodgson et al. 2009). Even if we can meet these assumptions, there are also risks that improved connectivity could hasten the extirpation of some species and communities by facilitating invasion by rapidly moving species which might outcompete, or at least substantially alter, existing communities (e.g., Burbidge et al. 2008; Jackson and Pringle 2010). Explicitly promoting connectivity might create a conservation bias towards preservation of species and communities that adapt through movement rather than those that adapt through behavioral or physiological changes. Fundamentally, this approach assumes that we possess enough knowledge about ecological connectivity to make wise decisions on how to best promote and sustain natural linkages. In many cases, we simply do not have this level of knowledge. 
Trade-offs

First, connectivity is not always positive with regard to conservation of biodiversity. Facilitating the ease with which individuals can move between conservation areas, can also expose conservation areas to the rapid transmission of deleterious influences such as diseases, invasive species or large-scale disturbance events. For example, reducing the spacing between coral reef marine protected areas (MPAs) might allow improved larval connectivity and therefore quicker recovery of reef populations following disturbance, but it also increases the risk that numerous MPAs are impacted by the same large coral bleaching or cyclone event, making recovery of the whole system more challenging (Almany et al. 2009). Second, there might be trade-offs between the optimal connectivity patterns for different species and communities (Gerber et al. 2005; Vos et al. 2008; McCook et al. 2009). A suite of multiple focal species likely to collectively serve as a proxy for the entire set of conservation features in a region should be used to develop a connectivity plan (Beier et al. 2008). Third, by adding an additional consideration when selecting and prioritizing conservation areas, it may be necessary to trade-off increased connectivity with other properties of the conservation area network, for instance, the total size and number of core conservation lands and waters, representation of different elements of biodiversity, or habitat quality (Hodgson et al. 2009). Fourth, connectivity might be achieved through changes in management of the surrounding matrix, but this strategy relies on management actions that might be largely beyond the control of conservation agencies and institutions, and thus would represent a major investment in outreach and cooperation with private landowners. In sum, corridors and connectivity have a long tradition in conservation planning even without worries about climate change, but their practical application and costliness relative to alternatives requires careful consideration in the planning process.

\section{Sustaining ecosystem process and function}

In its early years, systematic conservation planning was largely focused on conserving the patterns of biodiversity with little attention given to ecological process and function (Groves et al. 2002). Conservation planners and scientists increasingly promote incorporation of ecological processes and function (e.g., Leroux et al. 2007; Manning et al. 2009). In the climate adaptation arena, Halpin (1997) was among the first to recommend the need to manage for the maintenance of natural disturbance regimes such as fire as an adaptation response to climate change. More recently, Millar et al. (2007) suggested that for forests that are far outside historical ranges of variability in terms of fire regime or forest structure, it may be necessary to manage for future expected conditions as well as implement restoration treatments. In freshwater ecosystems, ecologists are calling for large-scale reconnection of floodplains through levee setbacks that will reduce anticipated flooding risks while allowing more natural flow regimes (Opperman et al. 2009). In marine ecosystems, shellfish restoration efforts can restore important ecosystem functions including nutrient removal, shoreline stabilization and coastal defense against rising sea level and storm surges (Beck et al. 2011).

Sustaining current and future ecosystem process and function may be at the challenging end of the adaptation spectrum, but it is not a new idea in conservation planning (Baker 1992). The Nature Conservancy, for example, has incorporated the conservation of ecological process in its ecoregional conservation plans for over a decade (Groves et al. 2002). 
Cowling et al. (1999) and Pressey et al. (2003) were among the first to test methods for incorporating ecological process in specific systematic planning efforts. Despite over 20 years of recommendations to place more emphasis on ecological process and function in conservation plans, challenges remain. Establishing explicit conservation goals and objectives for these processes and functions in the face of climate change is among the most significant of these. For example, in the Murray-Darling Basin in Australia, the Victorian Environmental Assessment Council (VEAC) compiled and synthesized data on natural flood requirements for all flood-dependent vegetation classes and rare and threatened species in major parts of the Basin (Aldous et al. 2011). Although VEAC had already recommended setting aside 4000 giga-liters every 5 years for environmental flows, new estimates of runoff that had taken climate change into account suggested that the amount of water available for environmental flows could be reduced as much as $32 \%$ over earlier projections. Even modest climate change scenarios implied that water necessary for natural overbank flows that sustain the ecosystem would not be available in many parts of the system and that new infrastructure would be required in the future to deliver those environmental flows (Aldous et al. 2011).

\section{Assumptions}

There are two important assumptions to the process and function approach that have limited its use. The first is that we have sufficient understanding and data on the most important ecological processes to design and implement conservation strategies for them (Possingham et al. 2005). Although ecologists increasingly understand the role of fire and nutrient cycling in many ecosystems, as well as the importance of natural flow regimes in aquatic ecosystems, many ecosystem processes and functions remain poorly understood. The second assumption is that we can identify spatial data (e.g., the spatial distribution of riparian areas) to serve as surrogates for these processes and functions (Klein et al. 2009) or models to simulate disturbance regimes that can be used in conservation planning exercises (Leroux et al. 2007). Significant progress is being made in this regard. In the Cape Floristic region of South Africa, for example, Pressey et al. (2003) were able to identify an extensive variety of ecological processes ranging from animal migrations to the movement of coastal sediments, and spatial surrogates to represent these processes in regional plans.

\section{Trade-offs}

Because an approach focused on sustaining process and function involves identifying new targets and objectives in systematic conservation planning, the trade-offs are potentially significant. Shifting conservation objectives from maintaining individual elements of biodiversity (e.g., species or habitats) towards maintaining specific ecological processes or functions may require compromising on both the extent and effectiveness of biodiversity representation within the networks of conservation areas that emerge from regional conservation plans (see Klein et al. 2009 for an exploration of potential trade-offs). Similarly, if this approach leads to setting priorities for areas that we otherwise might not conserve, such as degraded lands that are critical to certain functions, a potential trade-off is that the conservation of ecologically intact land and seascapes may be jeopardized. Despite these potential trade-offs, conservation plans with priorities based on both the representation of biodiversity and the underlying processes and functions that support it, are more likely to achieve lasting conservation results. 


\section{Capitalizing on opportunities emerging in response to climate change}

Opportunities for conservation planning that may emerge as climate changes will range from ecological to social. Climate change may improve conditions for some species, ecosystems, and processes of conservation concern, allowing conservation resources currently directed at these elements to be redirected elsewhere. Societal responses to climate change can provide novel opportunities to increase both the success and cost effectiveness of conservation. For example, strategies for REDD—Reduced Emissions from Deforestation and Forest Degradation (Angelsen 2008) use payments from developed countries to developing countries to reduce greenhouse gas emissions from deforestation and forest degradation. This approach provides a potentially powerful and well-funded mechanism to maintain ecologically intact forests that are also likely to have substantial biodiversity benefits, such as conserving greater numbers of species (Venter et al. 2009; Busch et al. 2010). In addition to these biodiversity benefits, increasing the representation and extent of ecosystem types under conservation management have been identified as two key principles for climate adaptation (Kareiva et al. 2008). While REDD itself is a climate change mitigation activity, using REDD to help conserve biodiversity at a regional scale is an adaptation strategy taking advantage of an emerging opportunity. In addition to REDD, opportunities might also emerge from carbon/ biodiversity off-sets (Kiesecker et al. 2010), renewable energy developments (Wiens et al. 2011), human responses to climate change (Hale and Meliane 2009), and perhaps other ecosystem service opportunities (Tallis et al. 2008). These opportunities could influence the priorities for conservation areas that emerge from systematic conservation planning processes, and plans may need to explicitly consider how such opportunities might best intersect with conservation priorities. For example, initial efforts to incorporate ecosystem services into systematic conservation planning are promising (Chan et al. 2006; Egoh et al. 2010) but may involve trade-offs with biodiversity conservation.

The climate change policy arena presents a special opportunity to focus on conservation actions that promote the ability of ecosystems, and the societies that depend on them, to deal with climate-induced changes. This approach is referred to as Ecosystem-Based Adaptation (EBA), a term favored by the International Union for the Conservation of Nature (IUCN; www.iucn.org/) and the Climate Action Network (www.climatenetwork.org/). These groups define EBA as: "a range of local and landscape scale strategies for managing ecosystems to increase resilience and maintain essential ecosystem services and reduce the vulnerability of people, their livelihoods and nature in the face of climate change" (CAN 2009). Strategies commonly proposed under the banner of EBA include maintaining or restoring wetlands and estuaries that help protect against flooding; maintaining coral reef systems that protect islands and coastlines from wave erosion; and protecting or restoring forests that can reduce flood damage and erosion from more frequent and severe storms while preserving access to clean water and food (Hale and Meliane 2009). In some cases, implementing these strategies is straightforward and involves actions similar to those necessary to establish most new conservation areas, except that in this case the focus is on conserving natural ecosystems that also provide a direct benefit to human communities.

EBA opportunities may represent the greatest departure from traditional systematic planning methods. For example, rather than planning to conserve a representative set of coral reef habitats in a region, we might choose to prioritize those reefs systems most critical for the protection of coastal human communities. To do this, we would need additional data not traditionally included in regional assessments such as the vulnerability of coastal communities to storm surges (e.g., USAID 2009) or the volume of carbon and rates of deforestation associated with implementing a REDD strategy (Venter et al. 2009). 


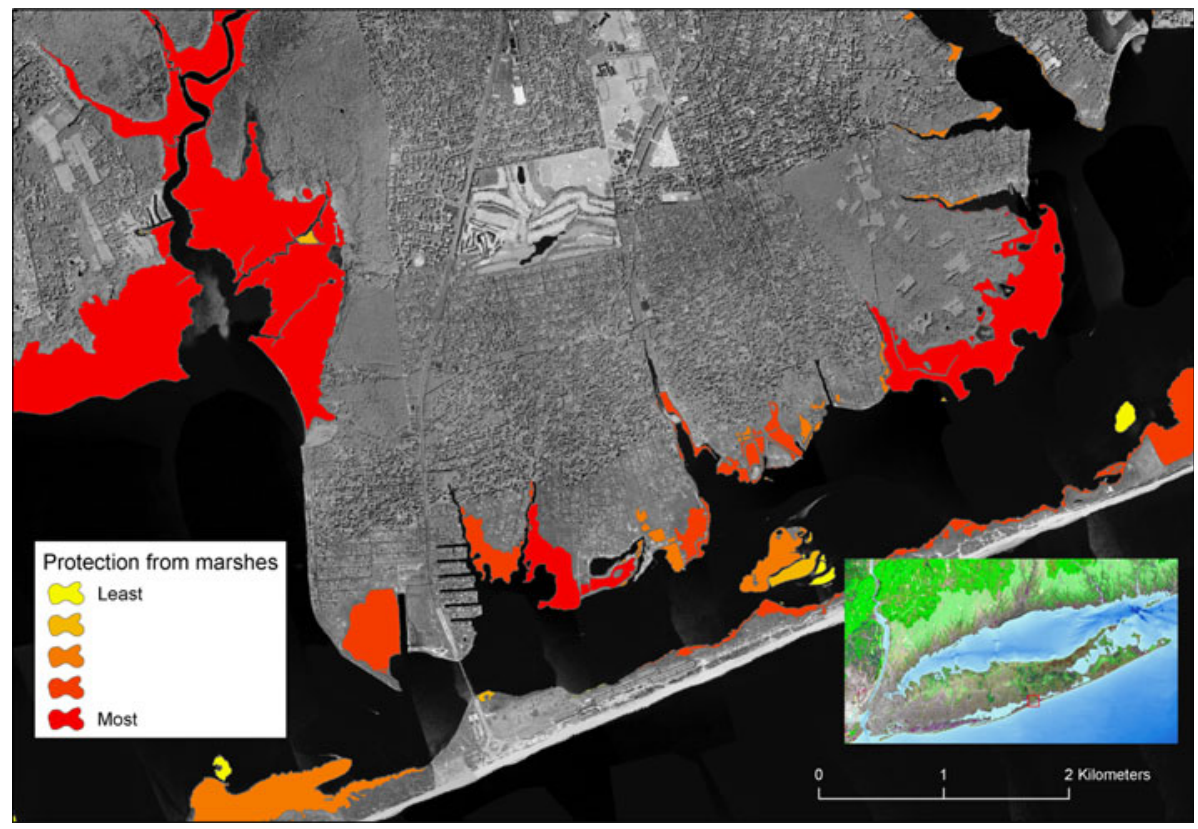

Fig. 4 Identification of natural ecosystems (marshes) that offer a range of protection to coastal human communities in Long Island, New York, with a Web mapping tool developed as part of a Coastal Resilience project (http://coastalresilience.org/). The tool helps explore climate change risks to coast communities and highlights area where mitigation and biodiversity conservation goals overlap

We will also likely need alternative decision support tools to communicate future climate scenarios and potential EBA solutions, such as interactive Web-based mapping applications (e.g., Ferdaña et al. 2010) (Fig. 4). Regional conservation plans can be used to identify the best places to implement EBA strategies. Early results are promising. For example, we increasingly recognize that we can re-operate dams to both improve their benefits to people and their natural flow regimes and connectivity for nature (Richter et al. 2010). In terrestrial systems, we now understand that the intensity and frequency of fire regimes are being amplified by climate change which may require larger areas to accommodate these disturbances and pro-active steps to "fireproof" local communities (Brown et al. 2004).

\section{Assumptions}

The value of including emerging opportunities in systematic conservation planning rests on at least two assumptions. The first is that conservation is always challenged for resources and opportunities and looking for ways to leverage investment or get greater return on the investment. The second, and related assumption, is that aligning conservation work with these emerging opportunities is efficient from a cost and implementation point of view and is not cancelled out by either the transaction costs of actively pursuing such opportunities, or the trade-offs described below. In the specific case of EBA opportunities, we assume that we can identify and conserve natural ecosystems that will improve resilience of both ecological and human communities even though this assumption is currently being debated (Feagin et al. 2010). In addition, using this approach assumes that we have sufficient 
knowledge to determine which ecosystems and communities are most vulnerable and what combination and placement of conservation areas will deliver the greatest benefits to both communities. Finally, some EBA strategies are dependent upon the provision of specific ecosystem services, yet the study and valuation of such services remains an emerging science (Kareiva et al. 2010).

\section{Trade-offs}

Trying to achieve conservation outcomes through alliances with activities not principally directed at conservation involves many trade-offs. By their very nature, these emerging opportunities are unlikely to be outright win-win situations for conservation because they include objectives in addition to those that are specific to biodiversity conservation (Venter et al. 2009). Consequently, conservation planners, scientists, and practitioners may have to be willing to compromise on conservation objectives in pursuit of these opportunities. Emerging opportunities may be accompanied by emerging challenges, such as new industries and sectors (e.g., biofuels; Fargione et al. 2009) arising in response to a changing climate that pose novel or additional impacts to biodiversity. These emerging opportunities and challenges could also be incorporated into the menu of opportunities and constraints.

\section{Data considerations}

Each of the approaches to climate change adaptation in systematic conservation planning may require the collection and inclusion of additional data sets (Table 1). These data sets

Table 1 Additional data for regional conservation assessments that may be needed to support the climate change adaptation approaches described in this document

\begin{tabular}{|c|c|}
\hline Adaptation approach & Additional data needed for regional assessments \\
\hline $\begin{array}{l}\text { Conserving the geophysical } \\
\text { stage }\end{array}$ & $\begin{array}{l}\text { Distribution of geophysical and topographic properties (e.g., bedrock types, } \\
\text { soil, elevation, aspect) }\end{array}$ \\
\hline Protecting climatic refugia & $\begin{array}{l}\text { Spatial distribution of current/historic refugia, and spatial distribution of } \\
\text { potential future refugia, projected climate change impacts and/or climate } \\
\text { change vulnerabilities }\end{array}$ \\
\hline Enhancing connectivity & $\begin{array}{l}\text { Knowledge of the connectivity requirements for key ecological targets and } \\
\text { the capacity to measure and compare the connectivity of different } \\
\text { conservation area designs }\end{array}$ \\
\hline $\begin{array}{l}\text { Sustaining ecosystem process } \\
\text { and function }\end{array}$ & $\begin{array}{l}\text { Natural range of variability of ecosystem processes, information on } \\
\text { disturbance regimes, dynamic models that simulate natural disturbance } \\
\text { regimes; spatial surrogates for ecological processes (e.g., location of } \\
\text { migration corridors of specific animals) }\end{array}$ \\
\hline Emerging opportunities & $\begin{array}{l}\text { Distribution of opportunities and constraints for those activities with } \\
\text { potential conservation benefits. For example, to take advantage of REDD } \\
\text { payments we would need data on the volume of carbon and the rates of } \\
\text { deforestation. We would also need an understanding of the conservation } \\
\text { benefits of land uses emerging from REDD (e.g., how well do areas re- } \\
\text { forested for carbon off-sets conserve biodiversity?). EBA strategies } \\
\text { require data on the distribution of key ecosystem services (e.g., } \\
\text { mangroves that provide protection from coastal storms), and the } \\
\text { vulnerability of human communities to climate change stressors (e.g., } \\
\text { coastal flooding) }\end{array}$ \\
\hline
\end{tabular}

For more detailed information on these data needs-see Game et al. (2010) 
are additional to, not in place of, data on the distribution of biodiversity, as well as on the opportunities and constraints on conservation action, which are required for all regional assessments. Future climate change projections can be readily explored and obtained from various sources, such as the Climate Wizard tool (Girvetz et al. 2009), but additional data, information and analyses are needed to conduct climate change impact or vulnerability analyses (IPCC 2007b; Ferdaña et al. 2010; Game et al. 2010; Glick and Stein 2010).

\section{Flexible management and understanding uncertainty}

To a large degree, incorporating adaptation in regional conservation plans involves acknowledging that we undertake conservation in a world where many species distributions, disturbance regimes, and ecological processes are changing at much faster rates than in the past and in ways we often have little certainty about. This recognition necessitates a shift in traditional planning along four lines:

(1) Recognizing that previous conservation planning approaches (Araújo 2009), strategies or projects may not be viewed as successful in the future depending upon how climate change impacts manifest themselves.

(2) Imbibing a willingness to constantly monitor, reassess, respond to change, and alter course in an adaptive fashion (Millar et al. 2007), including a re-consideration of the goals of a conservation project in the face of climate change.

(3) Changing perspectives on what biodiversity conservation means, and making a shift from a focus of conserving the current patterns of biodiversity to one that accepts dynamism, different ecological patterns and processes in the future.

(4) Being explicit, transparent and scientifically rigorous in our treatment of risk and uncertainty. There are many aspects of this uncertainty that are important for systematic conservation planning, including spatial, temporal, and model uncertainty. For example, Carvalho et al. (2011)accounted for model uncertainty in predicting species distributions of Iberian herptiles and applied return-on-investment analyses under various climate change scenarios to identify a set of robust conservation investments. Wintle et al. (2011) used uncertainty analyses combined with simple cost-effectiveness analyses to transparently evaluate different adaptation (ecological management) investments for minimizing species loss due to climate change impacts. Their approach allowed them to assess uncertainty in management costs, benefits, and implementation and make management recommendations that are robust to a range of uncertainty levels. Although these examples are focused on the uncertainty in ecological or natural communities, a major challenge for developing conservation plans that will accommodate future climate changes is the uncertainty involved in anticipating potential climate change impacts on both natural and human communities.

The strength of the approaches identified in this paper is that they are largely robust to these uncertainties. By delivering conservation solutions that would be good for biodiversity regardless of future climates, they represent "no-regrets" approaches. Although other approaches and strategies may be employed depending on the specific ways climate change occurs on-the-ground, these five general approaches provide a good foundation for regional biodiversity conservation. 


\section{Conclusions}

The five general approaches to climate change adaptation described here represent our best estimate of an appropriate strategic planning response to the challenges of climate change. They represent common sense approaches based on principles of ecology and conservation biology, are as far as possible robust to future uncertainties, and can be integrated now into systematic conservation planning efforts. Successful adaptation will require implementing approaches such as these now, but also systematically evaluating and adjusting these approaches as necessary (Grantham et al. 2010).

Provided that the assumptions and trade-offs of each approach are carefully evaluated, we are confident these approaches either individually or in combination can strengthen systematic conservation efforts and better position conservation agencies and organizations to achieve long-term conservation goals in the face of climate change.

Acknowledgments We thank P. Kareiva, M. Marvier, M. Conte, C. Pearl, and R. Seidl for reviewing and editing earlier versions of this manuscript. S. Shafer received support from the USGS Climate and Land Use Change Research \& Development Program. We also thank H. Possingham and an anonymous reviewer who provided comments and additional references that significantly improved the quality and comprehensiveness of this paper.

Open Access This article is distributed under the terms of the Creative Commons Attribution License which permits any use, distribution, and reproduction in any medium, provided the original author(s) and the source are credited.

\section{References}

Abrantes KG, Sheaves M (2010) Importance of freshwater flow in terrestrial-aquatic energetic connectivity in intermittently connected estuaries of tropical Australia. Mar Biol 157:2071-2086. doi:10.1007/ s00227-010-1475-8

Aldous A, Fitzsimons J, Richter B, Bach L (2011) Drought, floods, and freshwater ecosystems: evaluating climate change impacts and developing adaptation strategies. Mar Freshw Res 62:223-231

Almany GR, Connolly SR, Heath DD, Hogan JD, Jones GP, McCook LJ, Mills M, Pressey RL, Williamson DH (2009) Connectivity, biodiversity conservation and the design of marine reserve networks for coral reefs. Coral Reefs 28:339-351. doi:10.1007/s00338-009-0484-x

Anderson M, Ferree C (2010) Conserving the stage: climate change and the geophysical underpinnings of species diversity. PLoS ONE 5(7):e11554

Angelsen A (2008) Moving ahead with REDD: issues, options, and implications. CIFOR, Bogor

Araújo MB (2009) Climate change and spatial conservation planning. In: Moilanen A, Wilson KE, Possingham HP (eds) Spatial conservation prioritization: quantitative methods and computational tools. Oxford University Press, Oxford, pp 172-184

Araújo MB, Humphries CJ, Densham PJ, Lampinen R, Hagemmeijer WJM, Mitchell-Jones AJ, Gasc JP (2001) Would environmental diversity be a good surrogate for species diversity? Ecography 24:103-110

Ashcroft MB (2010) Identifying refugia from climate change. J Biogeogr 37:1407-1413

Ashcroft MB, Chisholm LA, French KO (2009) Climate change at the landscape scale: predicting finegrained spatial heterogeneity in warming and potential refugia for vegetation. Glob Change Biol 15:656-667

Baker WL (1992) The landscape ecology of large disturbances in the design and management of nature reserves. Landsc Ecol 7:181-194

Beck M, Brumbaugh DR, Airoldi L, Carranza A, Coen LD, Crawford C, Defeo O, Edgar GJ, Hancock B, Kay MC, Lenihan HS, Luckenback MW, Toropova CL, Zhang G, Guo X (2011) Oyster reefs at risk and recommendations for conservation, restoration, and management. BioScience 61:107-116

Beger M, Grantham HS, Pressey RL, Wilson KA, Peterson EL, Dorfman D, Mumby PJ, Lourival R, Brumbaugh DR, Possingham HP (2010) Conservation planning for connectivity across marine, freshwater, and terrestrial realms. Biol Conserv 143(3):565-575. doi:10.1016/j.biocon.2009.11.006 
Beier P, Brost B (2010) Use of land facets to plan for climate change: conserving the arenas, not the actors. Conserv Biol 24:701-710

Beier P, Majka DR, Spencer WD (2008) Forks in the road: choices in procedures for designing wildland linkages. Conserv Biol 22:836-851

Beier P, Spencer WD, Baldwin RF, McRae BH (2011) Towards best practices for developing regional connectivity maps. Conserv Biol 25:879-892

Berkelmans R, De'ath G, Kininmonth S, Skirving WJ (2004) A comparison of the 1998 and 2002 coral bleaching events on the Great Barrier Reef: spatial correlation, patterns, and predictions. Coral Reefs 23(1):74-83

Breshears DD, Cobb NS, Rich PM, Price KP, Allen CD, Balice RG, Romme WH, Kastens JH, Floyd ML, Belnap J, Anderson JJ, Myers OB, Meyer CW (2005) Regional vegetation die-off in response to global-change-type drought. Proc Natl Acad Sci USA 102:15144-15148

Breshears DD, Myers OB, Meyer CW, Barnes FJ, Zou CB, Allen CD, McDowell NG, Pockman WT (2009) Tree die-off in response to global change-type drought: mortality insights from a decade of plant water potential measurements. Front Ecol Environ 7:185-189

Brown TJ, Hall B, Westerling AL (2004) The impact of twenty-first century climate change on wildfire danger in the western United States: an applications perspective. Clim Change 62:365-388

Bruinderink GG, Van Der Sluis T, Lammertsma D, Opdam P, Pouwels R (2003) Designing a coherent ecological network for large mammals in northwestern Europe. Conserv Biol 17(2):549-557

Buckley LB, Jetz W (2008) Linking global turnover of species and environments. Proc Natl Acad Sci 105(46):17836-17841

Burbidge AA, McKenzie NL, Brennan KEC, Woinarski JCZ, Dickman CR, Baynes A, Gordon G, Menkhorst PW, Robinson AC (2008) Conservation status and biogeography of Australia's terrestrial mammals. Aust J Zool 56(6):411-422. doi:10.1071/zo08027

Busch J, Godoy F, Turner WR, Harvey CA (2010) Biodiversity co-benefits of reducing emissions from deforestation under alternative reference levels and levels of finance. Conserv Lett 4:101-115

CAN (2009) Position paper and briefing on the role of ecosystems in adaptation. Climate Action Network International, Washington

Carvalho SB, Brito JC, Crespo EG, Watts ME, Possingham HP (2011) Conservation planning under climate change: toward accounting for uncertainty in predicted species distributions to increase confidence in conservation investments in space and time. Biol Conserv 144:2020-2030

Chan KMA, Shaw MR, Cameron DR, Underwood EC, Daily GC (2006) Conservation planning for ecosystem services. PLoS Biol 4(11):e379

Cowling RM, Pressey RL, Lombard AT, Desmet PG, Ellis AG (1999) From representation to persistence: requirements for a sustainable system of conservation areas in the species-rich mediterranean-climate desert of southern Africa. Divers Distrib 5:51-71

Crooks KR, Sanjayan M (2006) Connectivity conservation: maintaining connection for nature. In: Crooks KR, Sanjayan M (eds) Connectivity conservation. Cambridge University Press, Cambridge, pp 1-20

Cross MS, Hilty JA, Tabor GM, Lawler JJ, Graumlich LJ, Berger J (2012) From connect-the-dots to dynamic networks: maintaining and enhancing connectivity as a strategy to address climate change impacts on wildlife. In: Brodie J, Doak D, Post E (eds) Wildlife conservation in a changing climate. University of Chicago Press, Chicago

Donner SD, Skirving WJ, Little CM, Oppenheimer M, Hoegh-Guldberg O (2005) Global assessment of coral bleaching and required rates of adaptation under climate change. Glob Change Biol 11: 2251-2265

Egoh B, Rouget M, Reyers B, Knight AT, Cowling RM, van Jaarsveld AS, Welz A (2007) Integrating ecosystem services into conservation assessments: a review. Economics 63:714-721

Egoh BN, Reyers B, Carwardine J, Bode M, O'Farrell PJ, Wilson KE, Possingham HP, Rouget M, deLange W, Richardson DM, Cowling RM (2010) Safeguarding biodiversity and ecosystem services in the Little Karoo, South Africa. Conserv Biol 24(4):1021-1030

Fargione J, Cooper TR, Flaspohler DJ, Hill J, Lehman C, Tilman D, McCoy T, McCleod S, Nelson EJ, Oberhauser KS (2009) Bioenergy and wildlife: threats and opportunities for grassland conservation. BioScience 59:767-777

Feagin RA, Mukherejee N, Shanker K, Baird AH, Cinner JE, Kerr AM, Koedam N, Sridhar A, Arthur R, Jayatissa LP, Seen DL, Menon M, Rodriguez S, Shamsuddoha M, Dahdouh-Guegas F (2010) Shelter from the storm? Use and misuse of coastal vegetation bioshields for managing natural disasters. Conserv Lett 3:1-11

Ferdaña Z, Newkirki S, Whelchel AW, Gilmer B, Beck MW (2010) Building interactive decision support to meet management objectives for coastal conservation and hazard mitigation on Long Island, New York, USA. In: Andrade Perez A, Herrera A, Fernandez B, Cazzolla Gatti R (eds) Building resilience 
to climate change: ecosystem-based adaptation and lessons from the field. IUCN, Gland, Switzerland, pp 73-79

Foden W, Mace G, Vie J-C, Angulo A, Butchart S, Devantier LM, Dublin H, Gutsche A, Stuart S, Turak E (2008) Species susceptibility to climate change impacts. In: Vie J-C, Hilton-Taylor C, Stuart SN (eds) The 2008 review of the IUCN red list of threatened species. IUCN, Gland, pp 77-88

Fridley JD (2009) Downscaling climate over complex terrain: high fine-scale spatial variation of nearground temperatures in a montane forested landscape (Great Smoky Mountains, USA). J Appl Meteor Clim 48:1033-1049

Fuller T, Munguia M, Mayfield M, Sanchez-Cordero V, Sarkar S (2006) Incorporating connectivity into conservation planning: a multi-criteria case study from central Mexico. Biol Conserv 133:131-142. doi:10.1016/j.biocon.2006.04.040

Game ET, McDonald-Madden E, Puotinen ML, Possingham HP (2008a) Should we protect the strong or the weak? Risk, resilience and the selection of marine protected areas. Conserv Biol 22:1619-1629

Game ET, Watts M, Wooldridge S, Possingham H (2008b) Planning for persistence in marine reserves: a question of catastrophic importance. Ecol Appl 18:670-680

Game ET, Groves CR, Andersen M, Cross M, Enquist CAF, Ferdana Z, Girvetz EH, Gondor A, Hall K, Higgins J, Marshall R, Popper K, Shafer SL (2010) Incorporating climate change adaptation into regional conservation assessments. The Nature Conservancy, Arlington, Virginia

Game ET, Lipsett-Moore G, Saxon E, Peterson N, Sheppard S (2011) Incorporating climate change adaptation into national conservation assessments. Glob Change Biol 17:3150-3160. doi:10.1111/ j.1365-2486.2011.02457.x

Gerber LR, Heppel SS, Ballantyne F, Sala E (2005) The role of dispersal and demography in determining the efficacy of marine reserves. Can J Fish Aquat Sci 62:863-871

Girvetz EH, Zganjar C, Raber GT, Maurer EP, Kareiva P, Lawler JJ (2009) Applied climate-change analysis: the Climate Wizard tool. PLoS ONE 4. doi:10.1371/journal/pone.0008320

Glick P, Stein B (2010) Scanning the conservation horizon: a guide to climate change vulnerability assessment. National Wildlife Federation, Washington DC

Grantham HS, Bode M, McDonald-Madden E, Game ET, Knight AT, Possingham HP (2010) Effective conservation planning requires learning and adaptation. Front Ecol Environ 8:431-437

Groves CR (2003) Draft a conservation blueprint: a practitioners guide to planning for biodiversity. Island Press, Washington DC

Groves CR, Jensen DB, Valutis LL, Redford KH, Shaffer ML, Scott M, Baumgartner JV, Higgins JV, Beck MW, Anderson MG (2002) Planning for biodiversity conservation: putting conservation science into practice. BioScience 52:499-512

Hale LZ, Meliane I (2009) Ecosystem-based adaptation in marine and coastal ecosystems. Renew Res J 25:21-28

Halpin PN (1997) Global climate change and natural area protection: management responses and research directions. Ecol Appl 7:828-843

Hansen L, Hoffman JR, Drew C, Mieelbirecht (2010) Designing climate-smart conservation: guidance and case studies. Conserv Biol 24:63-69

Heller NE, Zavaleta ES (2009) Biodiversity management in the face of climate change: a review of 22 years of recommendations. Biol Conserv 142:14-32

Higgins J, Bryer M, Khoury M, Fitzhugh T (2005) A freshwater classification approach for biodiversity conservation planning. Conserv Biol 19:432-445

Hilty J, Lidicker W Jr, Merenlender AM (2006) Corridor ecology: the science and practice of linking landscapes for biodiversity conservation. Island Press, Washington DC

Hodgson JA, Thomas CD, Wintle BA, Moilanen A (2009) Climate change, connectivity and conservation decision making: back to basics. J Appl Ecol 46:964-969

Hunter ML, Jacobson TLJ, Web T III (1988) Paleoecology and the coarse filter approach to maintaining biological diversity. Conserv Biol 2:375-385

IPCC (2007a) Climate change 2007: synthesis report. Contribution of working groups I, II and III to the fourth assessment report of the intergovernmental panel on climate change. IPCC, Geneva, Switzerland

IPCC (2007b) Climate change 2007: impacts, adaptation and vulnerability. Contribution of working group II to the fourth assessment report of the intergovernmental panel on climate change. Cambridge University Press, Cambridge, UK

Jackson CR, Pringle CM (2010) Ecological benefits of reduced hydrologic connectivity in intensively developed landscapes. Biosci 60:37-46. doi:10.1525/bio.2010.60.1.8

Jetz W, Rahbeck C (2002) Geographic range size and determinants of avian species richness. Science 297:1548-1550 
Kareiva P, Enquist CAF, Johnson A, Julius SH, Lawler JJ, Peterson B, Pitelka L, Shaw R, West JM (2008) Synthesis and conclusions. In: Julius SH, West JM (eds) Preliminary review of adaptation options for climate-sensitive ecosystems and resources. A report by the U.S. climate change science program and the subcommittee on global change research. U.S. Environmental Protection Agency, Washington DC

Kareiva P, Tallis H, Ricketts TH, Daily GC, Polasky S (2010) Natural capital: theory and practice of mapping ecosystem services. Oxford University Press, Oxford

Khoury M, Higgins J, Weitzell RE (2010) A conservation assessment of the Upper Mississippi River Basin using a coarse and fine filter approach. Freshw Biol 56:162-179

Kiesecker JM, Copeland H, Pocewicz A, McKenney B (2010) Development by design: blending landscapelevel planning with the mitigation hierarchy. Front Ecol Environ 8:261-266

Kirkpatrick JB (1983) An iterative method for establishing priorities for the selection of nature reserves: an example from Tasmania. Biol Conserv 25:127-134

Klein C, Wilson KA, Watts M, Stein J, Berry S, Carwardine J, Stafford Smith DM, Mackey B, Possingham HP (2009) Incorporating ecological and evolutionary processes into continental-scale conservation planning. Ecol Appl 19:206-217

Krosby M, Tewksbury J, Haddad NM, Hoekstra JM (2010) Ecological connectivity for a changing climate. Conserv Biol 24:1686-1689

Lawler JJ, Tear TH, Pyke C, Shaw MR, Gonzalez P, Kareiva P, Hansen L, Hannah L, Klausmeyer K, Aldous A, Bienz C, Pearsall S (2009) Resource management in a changing and uncertain climate. Front Ecol Environ 8:35-43

Le Quere C, Raupach MR, Canadell JG, Marland G, Bopp L, Ciais P, Conway TJ, Doney SC, Feely RA, Foster P, Friedlingstein P, Gurney K, Houghton RA, House JI, Huntingford C, Levy PE, Lomas MR, Majkut J, Metzl N, Ometto JP, Peters GP, Prentice IC, Randerson JT, Running SW, Sarmiento JL, Schuster U, Sitch S, Takahashi T, Viovy N, van der Werf GR, Woodward FI (2009) Trends in the sources and sinks of carbon dioxide. Nat Geosci 2:831-836. doi:10.1038/ngeo689

Leroux SJ, Schmiegelow FK, Cumming SG, Lessard RB, Nagy J (2007) Accounting for system dynamics in reserve design. Ecol Appl 17:1954-1966

Manning AD, Fischer J, Felton A, Newell B, Steffen W, Lindenmayer DB (2009) Landscape fluidity-a unifying perspective for understanding and adapting to global change. J Biogeogr 36:193-199. doi: 10.1111/j.1365-2699.2008.02026.x

Manning MR, Edmonds J, Emori S, Grubler A, Hibbard K, Joos F, Kainuma M, Keeling RF, Kram T, Manning AC, Meinshausen M, Moss R, Nakicenovic N, Riahi K, Rose SK, Smith S, Swart R, van Vuuren DP (2010) Misrepresentation of the IPCC $\mathrm{CO}_{2}$ emission scenarios. Nat Geosci 3:376-377

Margules CR, Pressey RL (2000) Systematic conservation planning. Nature 405:243-253

Marshall NA, Marshall PA, Tamelander J, Obura D, Malleret-King D, Cinner JE (2010) A framework for social adaptation to climate change: sustaining tropical communities and industries. IUCN, Gland

Mawdsley JR, O’Malley R, Ojima DS (2009) A Review of climate-change adaptation strategies for wildlife management and biodiversity conservation. Conserv Biol 2:1080-1089. doi:10.1111/j.1523-1739. 2009.01264.x

McCook LJ, Almany GR, Berumen ML, Day JC, Green AL, Jones GP, Leis JM, Planes S, Russ GR, Sale PF, Thorrold SR (2009) Management under uncertainty: guide-lines for incorporating connectivity into the protection of coral reefs. Coral Reefs 28:353-366. doi:10.1007/s00338-008-0463-7

McRae BH, Dickson BG, Keitt TH, Shah VB (2008) Using circuit theory to model connectivity in ecology and conservation. Ecology 89:2712-2724

Millar CI, Stephenson NL, Stephens SL (2007) Climate change and forests of the future: managing in the face of uncertainty. Ecol Appl 17:2145-2151

Opperman JJ, Galloway GE, Fargione J, Mount JF, Richter BD, Secchi S (2009) Sustainable floodplains through large-scale reconnection to rivers. Science 326:1487-1488. doi:10.1126/science.1178256

Parmesan C (2006) Ecological and evolutionary responses to recent climate change. Ann Rev Ecol Evol Syst 37:637-669. doi:10.1146/annurev.ecolsys.37.091305.110100

Poiani KA, Goldman RL, Hobson J, Hoekstra JM, Nelson KA (2011) Redesigning biodiversity conservation projects for climate change: examples from the field. Biodivers Conserv 20:185-201

Possingham HP, Farnklin J, Wilson KA, Regan TJ (2005) The roles of spatial heterogeneity and ecological processes in conservation planning. In: Lovett GM, Jones CG, Turner MG, Weathers KC (eds) Ecosystem function in heterogeneous landscapes. Springer, New York, pp 389-406

Pressey RL (2002) The first reserve selection algorithm—a retrospective on Jamie Kirkpatrick's 1983 paper. Prog Phys Geogr 26:434-441

Pressey RL, Hager TC, Ryan KM, Schwarz J, Wall S, Ferrier S, Creaser PM (2000) Using abiotic data for conservation assessments over extensive regions: quantitative methods applied across New South Wales, Australia. Biol Conserv 96:55-82 
Pressey RL, Cowling RM, Rouget M (2003) Formulating conservation targets for biodiversity pattern and process in the Cape Floristic Region, South Africa. Biol Conserv 112:99-127

Pressey RL, Cabeza M, Watts M, Cowling RM, Wilson K (2007) Conservation planning in a changing world. Trends Ecol Evol 22:583-592

Raupach MR, Marland G, Ciais P, Le Quere C, Canadell JG, Klepper G, Field CB (2007) Global and regional drivers of accelerating $\mathrm{CO}_{2}$ emissions. Proc Natl Acad Sci USA 104:10288-10293. doi: 10.1073/pnas.0700609104

Redford KH, Coppolillo C, Sanderson EW, Da Fonseca GAB, Dinerstein E, Groves CR, Mace G, Maginnis S, Mittermeier RA, Noss R, Olson D, Robinson JG, Vedder A, Wright M (2003) Mapping the conservation landscape. Conserv Biol 17:116-131

Richter BD, Postel S, Revenga C, Scudder T, Lehner B, Churchill A, Chow M (2010) Lost in development's shadow: the downstream human consequences of dams. Water Altern 3:14-42

Rowland EL, Davison JE, Graumlich LJ (2011) Approaches to evaluating climate change impacts on species: a guide to initiating the adaptation planning process. Environ Manage 47:322-337

Saxon E (2008) Noah's Parks: a partial antidote to the Anthropocene extinction event. Biodiversity 9:5-10

Saxon E, Baker B, Hargrove W, Hofman F, Zganjar C (2005) Mapping environments at risk under different global climate change scenarios. Ecol Lett 8:53-60

Schick RS, Lindley ST (2007) Directed connectivity among fish populations in a riverine network. J Appl Ecol 44:1116-1126. doi:10.1111/j.1365-2664.2007.01383.x

Sinervo B, Mendez-de-la-Cruz F, Miles DB, Heulin B, Bastiaans E, Cruz MVS, Lara-Resendiz R, MartinezMendez N, Calderon-Espinosa ML, Meza-Lazaro RN, Gadsden H, Avila LJ, Morando M, De la Riva IJ, Sepulveda PV, Rocha CFD, Ibarguengoytia N, Puntriano CA, Massot M, Lepetz V, Oksanen TA, Chapple DG, Bauer AM, Branch WR, Clobert J, Sites JW (2010) Erosion of lizard diversity by climate change and altered thermal niches. Science 328:894-899. doi:10.1126/science.1184695

Tallis H, Kareiva P, Marvier M, Chang A (2008) An ecosystem services framework to support both practical conservation and economic development. Proc Natl Acad Sci USA 105:9457-9464

USAID (2009) Adapting to coastal climate change - a guidebook for development planners. United States Agency for International Development, Washington

Venter O, Meijaard E, Possingham HP, Dennis R, Sheil D, Wich S, Hovani L, Wilson KA (2009) Carbon payments as a safeguard for threatened tropical mammals. Conserv Lett 2:123-129

Vos CC, Berry P, Opdam P, Baveco H, Nijhof B, O’Hanley J, Bell C, Kuipers H (2008) Adapting landscapes to climate change: examples of climate-proof ecosystem networks and priority adaptation zones. J Appl Ecol 45:1722-1731. doi:10.1111/j.1365-2664.2008.01569.x

West JM, Salm RV (2003) Resistance and resilience to coral bleaching: implications for coral reef conservation and management. Conserv Biol 17:956-967

Wiens JA, Bachelet D (2010) Matching the multiple scales of conservation with the multiple scales of climate change. Conserv Biol 24:51-62. doi:10.1111/j.1523-1739.2009.01409.x

Wiens JA, Fargione J, Hill J (2011) Biofuels and biodiversity. Ecol Appl 21:1085-1095

Williams P, Hannah L, Andelman SJ, Midgley G, Araujo M, Hughes G, Manne L, Martinez-Meyer E, Pearson R (2005) Planning for climate change: identifying minimum-dispersal corridors for the Cape Proteaceae. Conserv Biol 19:1063-1074

Willis KJ, Bhagwat SA (2009) Biodiversity and climate change. Science 326:806-807

Wilson KA, Underwood EC, Morrison SA, Klausmeyer KR, Murdoch WW, Reyers B, Wardell-Johnson G, Marquet PA, Rundel PW, McBride MF, Pressey RL, Bode M, Hoekstra JM, Andelman S, Looker M, Rondinini C, Kareiva P, Shaw MR, Possingham HP (2007) Conserving biodiversity efficiently: what to do, where, and when. PLoS Biol 5:1850-1861. doi:e22310.1371/journal.pbio.0050223

Wintle BA, Bekessy SA, Keith DA, van Wilgen BW, Cabeza M, Schroder B, Carvalho SB, Falcucci A, Maiorano L, Regan TJ, Rondini C, Boitani L, Possingham HP (2011) Ecological-economic optimization of biodiversity conservation under climate change. Nat Clim Change 1:355-359. doi:10.1038/ nclimate 1227 